A C G

publications
Bioorg. Med. Chem. Rep. 3:1 (2020) 1-14

Bioorganic \&

Medicinal

Chemistry

Reports

\title{
Telomere, telomerase and telomerase inhibitors
}

\author{
Yusuf Ataker $\odot$ and Rahime Simsek \\ Hacettepe University, Faculty of Pharmacy, Department of Pharmaceutical Chemistry, 06100, \\ Sihhiye-Ankara, Türkiye
}

(Received June 16, 2020; Revised July 12, 2020; Accepted August 17, 2020)

\begin{abstract}
Telomeres are DNA sequences with protective structure which are located at the ends of chromosomes. It is known that the telomere length is shortening after all cleavage in somatic cells, whereas in tumor cells this shortening does not occur, and the telomere length is protected. Telomerase is a DNA polymerase with a special structure. The components of its structure are hTR, hTERT and TP1. hTR and hTERT are the components that play a major role in providing continuity to the chromosome. In normal cells, there is almost no telomerase enzyme activity, except for germ cells and stem cells. On the other hand, 85-90\% of cancer cell and cancer cell lines highly express telomerase. Expression of telomerase enzyme contributes to the development of cancer cells. This situation makes telomerase an interesting structure for cancer treatment and it is also supposed that the compounds that target telomerase could be effective in anticancer treatment. Telomerase inhibitors cause apoptosis and cell aging as a result of the shortening of telomere length in telomerase positive cancer cells. In this study, together with the function of the telomerase enzyme, hTERT target inhibitors, hTR target inhibitors, gene and immune treatments directed to telomerase, as well as other telomerase inhibitor strategies in treatment were investigated.
\end{abstract}

Keywords: Telomere; telomerase; telomerase inhibitor; hTERT; anticancer. @2020 ACG Publications. All right reserved.

\section{Introduction}

Telomere word, derived from the Greek words telos (ends) and meros (parts), has a protective function for linear chromosomes ends. Telomere length is an important factor in cell viability and therefore overall health. ${ }^{1}$

Telomeres were shown for the first time in 1931 by Muller with Drosophila, but it has been possible to determine the synthesis and functions of telomeric DNA in recent years. Today, researches on the function, synthesis mechanisms and structure of telomeres in mold fungi, protozoa, animal and plant cells continue. Telomeres that protect the integrity of the chromosome; play a role in cell division, tumor formation, aging, and suppression of gene expression. ${ }^{2,3}$

The telomerase enzyme was first described by Greider and Blackburn in Tetrahymena in 1985, and then shown by Morin in human HeLa cells. Telomerases are found in embryonic stem cells, germ cells, cancer cells, and single cell eukaryotes. Studies have shown that telomerase activity is higher in tumor tissues compared to healthy tissues. In addition, various studies have been conducted to show the relationship between telomerase and the immune system and it has been determined that immune system is weakened by telomere loss as a result of aging. ${ }^{4-7}$

\footnotetext{
* Corresponding author: E-Mail: rsimsek@ hacettepe.edu.tr
} 


\section{Telomeres and Telomerase Enzyme}

Telomeres consist of repeating DNA sequences that are coated and closed by folding proteins at the terminal points of linear chromosomes. They are made up of thousands of Timin-Timin-AdeninGuanin-Guanin-Guanin (TTAGGG) sequences in human cells. ${ }^{2,8}$

In 1961, telomeres were found to be an important structure to protect genetic material during replication through telomere-binding protein and telomere-specific DNA sequences. In a study of human fibroblasts, "Telomere loss" was observed. The term "telomeres loss" refers to the shortening of telomeres at the ends of chromosomes. There are two different mechanisms to prevent telomere loss: In the first mechanism, telomeric repeat sequences are synthesized de novo using RNA primer by active telomerase which is the reverse transcriptase enzyme. The second mechanism takes place as a result of the extended telomere pathway. Aging occurs as a result of shortening. Telomeres that ensure the integrity of the chromosome; they also take part in tumor formation. ${ }^{2}$

\subsection{Telomerase Enzyme}

Telomerase enzyme (telomere terminal transferase, telomere deoxynucleotidyl transferase) is a special DNA polymerase with ribonucleoprotein structure. This enzyme, which is responsible for the synthesis of "TTAGGG" repeats on chromosomal ends, was first described by Greider and Blackburn in Tetrahymena. It was first demonstrated by Morin in HeLa cells. Telomerase enzyme is found in embryonic cells and stem cells, somatic cells do not have telomerase enzyme. It is reactivated in cancer cells. $^{2}$

Telomerase uses an internal template when placing specific steric barriers on catalysis and primary elongation. On the other hand, all other polymerases use an external template. In order to initiate DNA replication, the DNA polymerase needs the RNA primer with a 3'-hydroxyl donor group, at which time an "end replication problem" occurs.

During cell division, incomplete replication in telomeres leads to telomere shortening. This is called the "end replication problem". Continuous shortening of the telomere to a critical length results in DNA damage. As a result of DNA damage, cell death events called DNA damage response (DDR) occur, such as aging or apoptosis. On the other hand, proliferative cells use telomerase to solve this replication problem. As the DNA polymerase continues along the template thread, it breaks up at the ends of the chromosomes, leaving the newly synthesized DNA thread shorter than the original template. Telomerase and telomeres correct this problem by preventing the loss of genetically encoded information during mitosis by making a repetitive template to provide enzymatic repair at the chromosome end portions. ${ }^{1,4,8}$

\subsubsection{Components of Telomerase Enzyme}

Telomerase enzyme is a ribonucleoprotein consisting of three subunits, hTER, hTERT and TP1. Human telomerase enzyme RNA (hTER); de novo forms a template for telomere synthesis. Telomerase RNA synthesizes the single chain of telomere DNA using the complementary sequence of telomere DNA repeat. Human telomerase reverse transcriptase enzyme (hTERT); has a protein structure, is involved in the synthesis of phosphodiester bonds during DNA synthesis. TP1 consists of the human telomerase protein component. ${ }^{2,9}$

\subsubsection{Mechanism of Telomerase Enzyme}

DNA replication only takes place in the 5' to 3' direction, but an 8-12 base RNA fragment called "RNA primer" is required. The RNA primer forms the 3'-OH group necessary to bind the DNA polymerase. Thus, new DNA is formed in the 3 'direction, the RNA primer is removed and a gap is formed at the 5' end of the new double-stranded DNA molecule. This gap cannot be repaired by DNA polymerase. Due to this mechanism, at the end of each synthesis, the chromosome will be shortened by the length of the RNA primer. Telomerase enzyme adds repetitive sequences to the ends of the chromosomes to prevent telomere shortening after each replication. The added sequences are folded like 
a "hairpin" and hydrogen bonds are formed between the guanosines that are encountered. When the RNA primer is removed, a 3'-OH end is formed, creating a substrate for the DNA polymerase to fill the gap. DNA loss is prevented as a result of hairpin structure breakage and replication cycle. ${ }^{2}$

\subsection{Telomere Diseases}

Telomeres; it is thought to be associated with bone marrow failure, congenital dyskeratosis, acquired aplastic anemia, pulmonary fibrosis, liver disease, heart disease, aging and cancer. In recent years, heterozygous mutations in hTR and hTERT genes, which are components of telomerase, have been reported in bone marrow failure, congenital dyskeratosis and idiopathic pulmonary fibrosis syndromes. These diseases are characterized by short telomeres and short telomeres have been shown to be associated with the course and early onset of the disease. ${ }^{2}$ In studies comparing patients with primary mitochondrial disorders (such as diseases caused by mutations in the mitochondrial genome), secondary dysfunction (such as metabolic diseases and neurodegenerative diseases) and healthy individuals, patients have been shown to have shorter telomeres. Also; a relationship between oxidative stress, mitochondrial dysfunction and telomere shortening has been found in patients with major depressive disorder, particularly in women with high stress ${ }^{8,10}$

\subsubsection{Bone Marrow Failure}

Due to the defective telomere structure and repair, hematopoietic dysfunction occurs with severe or mild course anomalies. Even if telomere mutations are inherited, the course of the disease can change even in the family. ${ }^{8}$

\subsubsection{Congenital Dyskeratosis}

After the discovery of DKC1 mutations in the genes, telomeres have been shown to be short in all patients with congenital dyskeratosis. Although there is no clear relationship between specific mutations and phenotype, the severity of the disease was found to be high in patients with the shortest telomeres. In summary, congenital dyskeratosis is the result of an anomaly in the repair or maintenance of telomeres. $^{8}$

\subsubsection{Acquired Aplastic Anemia}

It has been found that some mutations in telomerase genes are associated with short telomere length and the enzymatic activity of the mutated telomerase is reduced. Telomere length is shorter and enzymatic activity is reduced in patients with acquired aplastic anemia. ${ }^{8}$

\subsubsection{Pulmonary Fibrosis}

In pulmonary fibrosis characterized by cough, shortness of breath, impaired gas exchange and decreased lung volume, telomerase mutations and short telomeres were also detected. ${ }^{8}$

\subsubsection{Liver Disease}

Liver complications after bone marrow transplantation and fibrotic processes such as hepatic cirrhosis indicate telomere loss. ${ }^{8}$

\subsubsection{Hearth Diseases}

The length of telomeres has also been associated with cardiovascular complications. $\mathrm{n}$ a study comparing healthy individuals with those with coronary artery disease (CAD), it was found that endothelial progenitor cell telomeres were shorter in patients. It has been shown to prevent oxidative DNA damage and telomere degradation after intensive antilipidemic therapy. The same has been 
observed for people with myocardial infarction (MI). There is some studies showing that telomere length is shorter in these patients than in healthy people. ${ }^{8}$

Regardless of age, telomeres are thought to play a role in the progression or onset of cardiovascular disease. Brouilette et al., Samani et al. showed that patients with CAD or MI had shorter telomere lengths compared to control groups of the same age and gender. ${ }^{11,12}$ However, it has not been established whether the shortening of the telomere length is a cause or a consequence of the onset of CAD. ${ }^{13}$

Recent studies suggesting the hypothesis that shortening telomere length may be an important factor in the onset and development of CAD, it has also been shown that telomere length is associated with increased mortality in CAD patients, independent of other cardiovascular risk factors. ${ }^{13}$

\subsubsection{Telomerase Enzyme and Aging}

With some exceptions, parents are delivered with full-length telomeres, regardless of age since telomerase is actively present in the germ line and developing fetus. In addition, telomerase is downregulated in somatic tissues before birth and as a result, telomeric DNA loss occur. ${ }^{7}$

The length of telomeres at birth is similar in both women and men, but telomeres shorten more slowly in women than men during life. Because men are more sensitive to reactive oxygen types than women. ${ }^{14}$ Telomere lengths in human blood have been associated with health and life span in people 60 years and older. ${ }^{15}$ In addition, calculating the percentage of short telomeres rather than averaging telomere lengths plays a more important role in predicting lifetime. ${ }^{16}$

As a result of increasing evidence, it is understood that telomere biology plays a central role in many aspects of aging. ${ }^{17}$ The relationship between aging and telomeres can be explained by the hypotheses: Somatic tissue telomere lengths of older people are shorter compared to younger people, telomere lengths of children are shorter compared to the control group of the same age in early aging disease. $^{2}$

\subsubsection{Telomerase Enzyme and Cancer}

After the discovery of the telomerase enzyme, telomerase was detected in normal tissues and cancer, and functional characterization and cloning of the core telomerase genes were performed. Telomerase is expressed in most tumors and cancer stem or stem-like cells are also suggested to be telomerase positive. Studies have reported that the frequency of telomerase positive tumors is $85 \%$. $^{7,18}$

The fact that tumors are less likely to develop resistance to telomerase-based treatments reveals the importance of telomerase. ${ }^{19}$ Temporary or low expression of telomerase reduces the likelihood of toxicity to telomerase-based drugs in normal tissues, including normal stem cells, and provides tumor specificity. These factors indicate that cancer drugs based on the telomerase enzyme inhibition may have a wide therapeutic window. ${ }^{7}$ After understanding the importance of telomerase activation in the process of transforming healthy cells into tumor cells, one of the most important approaches to develop anticancer drugs is to obtain compounds that act by an antitelomerase mechanism. ${ }^{20}$

In a study, it was found that the telomerase activities and telomere lengths of the cells showed significant changes in twenty-four different types of cancer compared to normal cases. ${ }^{21}$ Benign tumors do not have telomerase enzyme activity and return to their early stages as telomere length decreases. In the more aggressive metastatic tumors, high telomerase enzyme activity has been demonstrated. ${ }^{3}$ Determining the activity of telomerase enzyme in more than $85 \%$ of different types of tumors investigated to date shows that telomerase is reactivated in immortal cells. ${ }^{21}$

\section{Telomerase Inhibitors}

Due to its potential anticancer properties, many telomerase inhibitors have been developed and their activities have been investigated. Telomerase inhibitors can be administered with or after other treatments to prevent reproduction of resistant cancer cells. Telomerase inhibitors have the advantages of reaching the tumor directly without being destroyed, encapsulated so that they can remain in the bloodstream and taken into a high rate of malignant cells. Although they are tumor specific, they can cause side effects, especially in cells with telomerase enzyme activity (proliferative cells, hematopoietic cells, active T and B lymphocytes and germ cells). ${ }^{1,2}$ 
Telomerase inhibitors can be grouped as follows:

a) Telomerase Catalytic Subunit (hTERT) Targeting Inhibitors

Dominant Negative hTERT

hTERT Transcription Inhibitors

Small Molecule Inhibitors

b) Telomerase RNA Component (hTR) Targeting Inhibitors

Peptide Nucleic Acids (PNA)

Antisense Oligonucleotides

Hammerhead Ribozymes

c) Immune Therapy for Telomerase

d) Gene Therapy for Telomerase

e) Other Telomerase Inhibitors

G-quadruplex Stabilizer Ligands

Heat Shock Protein 90 (HSP90) Inhibitors

\subsection{Telomerase Catalytic Subunit (hTERT) Targeting Inhibitors}

\subsubsection{Dominant Negative hTERT}

Dominant negative mutants act as genetic dominant mutations because they show their effects in the presence of wild-type gene products, and because their effects are inhibitory, such mutations are called dominant negative. ${ }^{22}$

In the case of a monomeric protein that has a single function (eg an enzyme), the dominant negative mutant can encode a gene product that binds the same substrate with the wild type enzyme (preferably more desirably) but lacks catalytic activity. Thus, this mutant can compete with the wildtype enzyme for the substrate. If the enzymatic reaction is potentially limited to the available substrate concentration and the mutant enzyme can be expressed more than the wild type enzyme, any functional outcome of enzymatic wild type activity could be effectively inhibit. ${ }^{23}$

\subsection{2. hTERT Transcription Inhibitors}

The hTERT promoter includes a variety of transcription factor binding sites, including basic helix-loop-helix (bHLH) binding sites that are involved in hTERT transcriptional activation by c-Myc. c-Myc provides effective activation of hTERT transcription. The Tax protein has been shown to suppress hTERT expression through the second bHLH binding site on the hTERT promoter. Thus, the effect of Tax protein on hTERT activation of bHLH c-Myc was investigated. The inhibitory effect in competition with c-Myc in the hTERT promoter resulted in decreased telomerase activity of cells expressing the Tax protein. Tax protein is expressed only during the premalignant phase of adult $\mathrm{T}$ cell leukemia / lymphoma, and hTERT suppression with Tax protein is limited to early carcinogenesis. ${ }^{24}$

Demethylation reagents have been a potential anticancer drugs for some types of cancer. The demethylation reagent, 5-azacitidine (5-aza-CR) (Figure 1), significantly reduced the telomerase activity in some cells. Reverse transcription-polymerase chain reaction (PCR) analyzes show that inhibition of telomerase enzyme activity is associated with down regulation of hTERT mRNA expression. Transient expression analysis shows that 5-aza-CR suppresses the transcriptional effect of the hTERT promoter and that the enhancer box (E-box) in the core promoter is involved in this down regulation. In addition, 5-aza-CR has been shown to reactivate p16 expression and suppress c-Myc expression in some cells. These results show that 5-aza-CR inhibit the activity of the telomerase enzyme with the transcriptional suppression of hTERT. ${ }^{25,26}$ 
<smiles>[Y]C=[V]</smiles>

Figure 1. Structure of 5-azacytidine

The orphan receptor chicken ovalbumin upstream promoter-transcription factor II (COUP-TFII) is a transcription factor that plays an important role in cellular differentiation and development. COUPTFII has been shown to be regulated on different cancer cell lines. Luciferase assays have shown that COUP-TFII can suppress the transcription of the hTERT promoter. By stably introducing COUP-TFII into HeLa cells, both endogenous hTERT expression and telomerase activity are reduced. In addition, it has been shown that human COUP-TFII can specifically interact with the hTERT promoter and partially through the E-box, hTERT expression can be suppressed. ${ }^{27}$

Breast cancer type 1 sensitivity protein (BRCA1) plays a role in DNA repair, tumor suppression, cell cycle control, and transcriptional regulation. ${ }^{28}$ In breast cancer cells, BRCA1 has been observed to have an endogenous relationship with Nmi (a protein that interacts with $\mathrm{N}-\mathrm{Myc}$ ). In vitro and in vivo studies demonstrated that BRCA1 interacts with Nmi by binding to two specific regions of Nmi, amino acid residues 298-683 and 1301-1863. The mediator molecule that incorporates c-Myc into the Nmi-cMyc-BRCA1 complex is Nmi. The resulting triple complex inhibits c-Myc-induced hTERT promoter activity in breast cancer cells. ${ }^{29}$

\subsubsection{Small Molecule Inhibitors}

hTERT-specific active site inhibitors, BIBR1532 (Figure2) is one of the most promising agents. BIBR1532 is a non-nucleotidic small synthetic molecule that competitively binds to the active site of hTERT and inhibits the telomerase enzyme. BIBR1532 acts independently from the active site of telomerase, preventing DNA from binding to the telomerase enzyme and at the same time preventing telomere thread from crossing the 5 'end of the DNA thread. Telomeres remain the same size and degrade with the DNA strand not growing. Studies have shown that BIBR1532 has no effect on cells other than tumor cells and that it inhibits telomerase enzyme dose-dependent. Positive results were obtained with BIBR1532 in preclinical studies in fibrosarcoma, prostate and breast cancer cell lines. The disadvantages are limited bioavailability and high doses of inducing cytotoxicity. ${ }^{1,30-32}$<smiles>C/C(=C\C(=O)Nc1ccccc1C(=O)O)c1ccc2ccccc2c1</smiles>

Figure 2. Structure of BIBR1532 (2-[(E)-3-naphthalen-2-yl-but-2-enoylamino]-benzoic acid)

\subsection{Telomerase RNA Component (hTR) Targeting Inhibitors}

\subsubsection{Peptide Nucleic Acids (PNAs)}

If the PNA, which contains a complementary sequence to the RNA sequence of the human telomerase enzyme, is replaced with neutral $N$-(2-aminoethyl)glycine unit (Figure3) containing modified nucleotides, instead of the negatively charged deoxyribose-phosphate unit, the telomere template region of hTR can be inhibited by complementary PNA oligonucleotides. PNAs resistant to 
degradation by proteases or nuclease provide an effective inhibition in vitro conditions and have been found promising for the treatment of people with tumors. ${ }^{2,33}$

PNA can be hybridized with complementary RNA or DNA sequences with very high selectivity and affinity. The thermal stability of DNA/PNA hybrids is greater than analog DNA/DNA hybrids due to electrostatic repulsion and possible entropic effects due to limited rotation around the amide backbone. Assuming that the PNA portion of the inhibitor is bound to the RNA template, it is likely that the peptide portion will interact with the RNA or protein towards the attachment site of the telomerase. Although the required dose of 11-13 base length inhibition of human telomerase has been determined with PNAs, poor solubility and poor uptake properties in aqueous buffer limit direct therapeutic use of PNA. ${ }^{34,35}$<smiles>NCCNCC(=O)O</smiles>

Figure 3. $N$-(2- aminoethyl)glycine

\subsubsection{Antisense Oligonucleotides}

The antisense oligonucleotide approach targeting the telomerase enzyme was first derived to block the translation of the mRNA with a complementary sequence to detect RNA. Today the most successful antisense oligonucleotide developed is GRN163L. N3-P5-thiophosphoramidate oligonucleotides (GRN163L) targeting the active region template of hTR have been developed as a new class of telomerase inhibitors. Although the formation of resistance mechanisms is not expected in oligonucleotide products, it is a disadvantage that a long and continuous inhibition is required to see the clinical response after drug administration. ${ }^{7,30,36,37}$

Studies show that GRN163 and GRN163L inhibit telomerase enzyme activity and tumor cell growth in vivo and in vitro depending on dose. The efficacy and potency of the lipid-conjugated antagonist GRN163L is greater than the non-lipidized parent compound GRN163. Inhibition of telomerase activity with GRN163L resulted in faster cell growth and telomere loss compared to GRN163. GRN163L has a high affinity for the single-strand template region of the telomerase enzyme, and after binding it strongly blocks telomerase access to telomeres. As a result of numerous preclinical studies, the pharmacodynamic and pharmacokinetic properties of GRN163L have been proven to be good, effective, safe and strong, and clinical studies are ongoing. ${ }^{7,38}$

\subsubsection{Hammerhead Ribozymes}

Hammerhead ribozymes are small RNA molecules that have specific endoribonuclease activity. They consist of a catalytic core surrounded by antisense sequences that are involved in the recognition of the target region. Three different ribozyme structures targeting the $3^{\prime}$ ends of different sequences in hTR have been used, and ribozyme targeting the template region has proven to be most effective in reducing the activity of the telomerase enzyme, leading to a shorter telomere length over four weeks. ${ }^{33}$

\subsection{Immune Therapy for Telomerase}

Telomerase enzyme is a new and universal target for cancer treatment and anticancer vaccination. ${ }^{39}$ It is known that $\mathrm{T}$ cells of the human immune system can recognize telomerase. Telomerase vaccines offer the potential to stimulate the rapid killing of cancer cells by increasing the activity of telomerasespecific cytotoxic $(\mathrm{CD} 8+)$ and / or helper $(\mathrm{CD} 4+) \mathrm{T}$ cells. ${ }^{7,40}$

Typically, antigen presenting cells (APCs) are exposed to relatively higher levels of TERTencoding gene products or peptide fragments in vivo or ex vivo. APCs then enable the growth and activation of pure or memory TERT-specific $\mathrm{T}$ cells that cooperate to kill cancer cells with TERT peptides on their surface. ${ }^{7}$ 
The most advanced products, GRNVAC1 and GV1001, are designed to reveal both CD8 and CD4 responses. GV1001 is a peptide corresponding to a sequence derived from the active region of hTERT. Contains hTERT 611-626 (H - Glu - Ala - Arg - Pro - Ala - Leu - Leu - Thr - Ser - Arg - Leu - Arg - Phe - Ile - Pro - Lys - OH) sequence. ${ }^{41,}{ }^{42}$ With GV1001 vaccination, potentially combined CD8 + and CD4 + T cell responses may occur. These $\mathrm{T}$ cell responses are thought to be of great importance in generating long-term memory and destroying tumors. ${ }^{43}$

GV1001 is a lyophilized peptide for intradermal injection. The mechanism of action depends on the effective presentation of GV1001-related epitopes to T cells, peptide uptake of APCs in the skin and migration of these cells to regional lymph nodes. In addition, peptides can be rapidly degraded before being taken up by APCs, and peptide presentation in a non-inflammatory environment can induce tolerance rather than immunity. In order to withstand these difficulties, it is recommended to inject GMCSF adjuvant 5-15 minutes before GV1001. ${ }^{44}$

Dendritic cells (DCs), the most effective APCs, are increasingly used in cancer immunotherapy to improve immune responses. GRNVAC1 is a dendritic cell vaccine that elicits immune responses through CD8 + and CD4 + T cells. It consists of immature DCs and hTERT, ex vivo transfected with a complete mRNA sequence. Lysosomal associated membrane protein (LAMP-1) can easily divert hTERT into a lysosome, which can easily decompose into peptides and lead to a better immune response. ${ }^{30,45,46}$

Continuous development of telomerase targeted immunotherapy is expected. In addition, further clinical studies are needed to establish a broader basis for antitelomerase-based cancer treatment and to integrate this into the immunological treatments of cancer. ${ }^{47}$

\subsection{Gene Therapy for Telomerase}

Gene therapy is a method aimed at treating diseases such as cancer by transmitting therapeutic DNA to the patient's cells. DNA encoding a therapeutic effect is delivered to the target cells. As a result, DNA is expressed by cell mechanisms that form a protein that can result in apoptosis. Genes can be delivered through oncolytic viral vectors and can include suicide genes or enzymes that metabolize prodrugs. Although gene therapy is significantly tumor-specific, there are often complex and special production / formulation challenges and the immunological response to the vector system may limit dosing. The main challenge is the delivery of the gene vector to cancer cells in the body. 7,48

There are adenoviral vectors designed only to enter cells that have telomerase activity and to kill tumor cells. These vectors have a TERT promoter that provides adenovirus replication. In this case, the virus reproduces excessively in telomerase-positive cells, thereby avoiding normal cells. After replication of the virus, the tumor cell breaks down and viral particles spread to neighboring cells. This approach is known as the adenoviral (hTERTp TRAD) gene therapy approach capable of tumor-specific replication. An example of telomerase-mediated virus therapy is Telomelysin (OBP-301), an oncolytic adenovirus modified with the hTERT promoter. In preclinical studies, OBP-301 has shown antineoplastic activity in various cancer cells. ${ }^{48,49}$

In suicide gene therapy (Ad-hTR-NTR / CB1954) (Figure4), also called "gene-directed enzyme prodrug therapy", the enzyme nitroreductase (NTR) provides the conversion of non-toxic prodrug CB1954 (5-(aziridin-1-yl)-2,4-dinitrobenzamide) to its active cytotoxic form. Suicide gene therapy targets only tumor cells, similar to oncolytic gene therapy. There are three general steps to this approach: The first is to target the vector. The second step is transfection of the vector carrying the gene encoding an enzyme directed by hTERT into the cells. The final step is the need for a prodrug activated by an enzyme, causing toxins to be released into the cytoplasm, resulting in the death of telomerase-positive cells. ${ }^{48,50,51}$<smiles>NC(=O)c1cc(N2CC2)c([N+](=O)[O-])cc1[N+](=O)[O-]</smiles>

Figure 4. Structure of CB1954 (5-(aziridin-1-yl)-2,4-dinitrobenzamide) 
Although gene therapy (oncolytic vector or suicide gene) shows some promising results, this strategy does not appear to be as effective as oligonucleotides or vaccines. ${ }^{48}$

\subsection{Other Telomerase Inhibitors}

\subsubsection{G-quadruplex Stabilizer Ligands}

G-quadruplex stabilizer ligands are potent ligands that prevent catalytic activity by acting on the telomerase enzyme. These compounds stabilize or regulate the G-quadruplex structure by preventing the opening of telomeric ends to telomerase. G-quadruplex ligands also cause telomere-related proteins to separate, leading to telomere dysfunction. Most G-quadruplex stabilizers contain a polycyclic heteroaromatic structure. The most studied G-quadruplex ligands are telomestatin (Figure 5), BRACO19 (N,N'-(9-\{[4-(dimethylamino)phenyl]amino\}acridine-3,6-diyl)bis(3-pyrrolidin-1-ylpropanamide)) (Figure6) and RHPS4 (3,11-difluoro-6,8,13-trimethyl-quino[4,3,2-kl]acridinium methylsulfate) (Figure7). They inhibit the telomerase enzyme by activating DNA damage responses similar to those that are activated in response to dsDNA breaks. ${ }^{30,52}$

Telomestatin specifically interacts with and stabilizes the intramolecular G-quadruplex structure. Inhibition of telomerase activity occurs by binding of two telomestatin molecules to the intramolecular G-quadruplex structure..$^{53}$

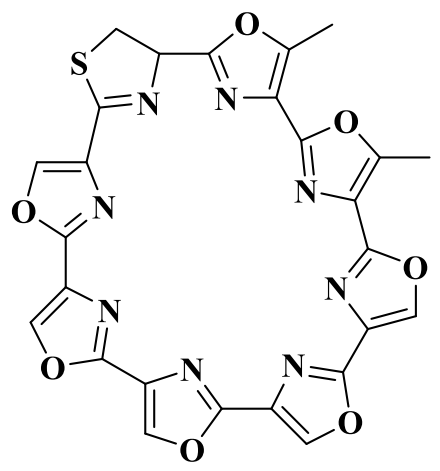

Figure 5. Structure of telomestatin ${ }^{52}$

BRACO-19 suppresses proliferation in human glioblastoma cells and reduces telomerase activity in parallel with the displacement of telomerase from the nucleus to the cytoplasm. ${ }^{54}$<smiles>CN(C)c1ccc(Nc2c3ccc(NC(=O)CCN4CCCC4)cc3nc3ccc(NC(=O)CCN4CCCC4)cc23)cc1</smiles>

Figure 6. Structure of BRACO-19

In vitro studies in cancer cells related to the biological effects of RHPS4 have shown that the drug produces cumulative antiproliferative effects in MCF-7 breast cancer cells, induces aging by inhibiting growth and provides shortening in telomere length. The shortening of telomere length is good evidence that telomerase enzyme inhibition and/or enzyme displacement from telomere after stabilization of G-quadruplex by RHPS4 in these cells. ${ }^{55}$ 
<smiles>CO[Sb]([O-])(O)O[Na]</smiles>

Figure 7. Structure of RHPS4

\subsubsection{Heat Shock Protein 90 (HSP90) Inhibitors}

HSP90 is a molecular chaperone. This structure, which allows cancer cells to grow and survive, is responsible for the regulation and folding of essential proteins. HSP90, contained in multi-chaperone complexes dependent on ATP hydrolysis, is grown in tumor cells. HSP90 inhibitors cause disruption and loss of HSP90 complex stabilizations by down-regulating many tumor proteins and modulating signaling in tumors. HSP90 is essential for telomerase activation and development. ${ }^{30,56}$

It was shown to block active telomerase components by inhibition of HSP90 function by Geldanamycin (GA). This suggests that targeting telomerase components can be a very interesting way to inhibit telomerase. In addition to its other effects on HSP90, it blocks ATP-dependent binding of the HSP90, thereby disrupting the chaperone device and inhibiting telomerase. Due to the high hepatotoxicity and limited solubility of GA, 17-allylamino-17-dimethoxygeldanamycin (17-AAG) and 17- [2- (dimethylamino) ethyl] amino-17-demethoxygeldanamycin (17-DMAG) analogs have been developed (Figure 8)..$^{77-61}$

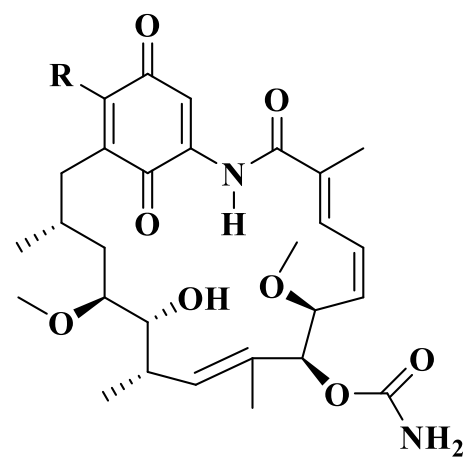

Figure 8. Geldanamycin structure $\left(\mathrm{R}=\mathrm{CH}_{3} \mathrm{O}-\right)$ and 17-substituted analogs (17-AAG, $\mathrm{R}=$ $\mathrm{CH}_{2}=\mathrm{CHCH}_{2} \mathrm{NH}-$ and 17-DMAG, $\left.\mathrm{R}=\left(\mathrm{CH}_{3}\right)_{2} \mathrm{NCH}_{2} \mathrm{CH}_{2} \mathrm{NH}-\right)$

\section{Conclusion}

Telomeres are repeated DNA sequences at the ends of the chromosomes. Telomere loss due to cell division is prevented by the addition of repeating sequences through the telomerase enzyme to the ends of the chromosomes. After clarifying the structure and function of telomerase enzyme and telomere, it was understood that these structures play a role in various diseases such as cancer, aging and cardiovascular diseases.

Telomerase enzyme inhibition is an important target in cancer treatment since telomerase enzyme is found in more than $85 \%$ of tumors and is not found in somatic cells. With the increase in research with telomerase inhibitors in cancer treatment, the importance and interest of telomerase inhibitors increase. Understanding the importance of telomerase in cancer treatment has made telomerase a target for developing personalized cancer therapeutics. With the use of telomerase 
inhibitors in combination with standard therapies, more effective results have been obtained in telomere shortening and tumor mass reduction. In addition, it is aimed to prevent resistance and tumor recurrence with combined treatment compared to single agent treatment. In clinical studies, telomerase inhibitors have been shown to be safe and well tolerated. These findings also contribute positively to the development of telomerase inhibitors. Further clinical studies of small molecule telomerase inhibitors, oligonucleotides and immunotherapeutics as anticancer agents are ongoing. However, no antitelomerase anticancer drug has yet been approved for clinical use by the U.S. Food and Drug Administration (FDA), since the clinical response occurs long after administration of the drug.

Technological advances and biological insight offered new opportunities in drug discovery, and efforts to develop new telomerase inhibitors have also increased. With the understanding of telomere biology and telomerase functions, new diagnostic methods and effective potential anticancer compounds have emerged. As a result of electron microscopy studies, the telomerase structure is better understood with the 3D model of human telomerase enzyme. This development will lead to the design of rational telomerase inhibitors and the emergence of more selective and active compounds with increased bioavailability.

\section{ORCID}

Rahime Simsek: 0000-0002-8467-6336

Yusuf Ataker: $\underline{000-0002-3775-3271}$

\section{References}

[1] Saraswati, A.P.; Relitti, N.; Brinidis, M.; Gemma, S.; Zistere, D.; Butini, S.; Campiani, G. Raising the bar in anticancer therapy: recent advances in, and perspectives on, telomerase inhibitors. Drug Discov. Today 2019, 24(7), 1370-1388.

[2] Güzelgül, F.; Aksoy, K. Telomeraz enziminin tanı ve tedavide kullanım alanı. Arşiv Kaynak Tarama Derg.. 2011, 20(2), 69-88.

[3] Güneri, M.; Aras, S.; Cansaran, D.D. Telomerlerin yaşlanma ve kanser ilişkisindeki rolü. Türk Hijyen Deney. Biyol. Derg. 2009, 66(4), 187-195.

[4] Greider, C.W. Telomere length regulation. Annual Rev. Biochem. 1996, 65(1), 337-365.

[5] Greider, C.W.; Blackburn, E.H. Identification of a specific telomere terminal transferase activity in tetrahymena extracts. Cell 1985, 43(2), 405-413.

[6] Andrews, N.P.; Fujii, H.; Goronzy, J.J.; Weyand, C.M. Telomeres and immunological diseases of aging. Gerontology 2010, 56(4), 390-403.

[7] Harley C.B. Telomerase and cancer therapeutics. Nature Rev. Cancer 2008, 8(3), 167-179.

[8] Calado, R.T.; Young, N.S. Telomere diseases. NEJM. 2009, 361(24), 2353-2365.

[9] Cairney, C.; Keith, W. Telomerase redefined: integrated regulation of hTR and hTERT for telomere maintenance and telomerase activity. Biochimie 2008, 90(1), 13-23.

[10] Zheng, Q.; Huang, J.; Wang, G. Mitochondria, telomeres and telomerase subunits. Front. Cell Dev. Bio. 2019, 7, 274.

[11] Brouilette, S.; Singh, R.K.; Thompson, J.R.; Goodall, A.H.; Samani, N.J. White cell telomere length and risk of premature myocardial infarction. Arterioscler. Thrombos. and Vascular Bio. 2003, 23(5), 842846.

[12] Samani, N.J.; Boultby, R.; Butler, R.; Thompson, J.R.; Goodall, A.H. Telomere shortening in atherosclerosis. The Lancet 2001, 358(9280), 472-473.

[13] Saliques, S.; Zeller, M.; Lorin, J.; Lorgis, L:; Teyssier, J.-R.; Cottin, Y.; Luc, R.; Vergely, C.Telomere length and cardiovascular disease. Arch. Cardiovas. Disease. 2010, 103(8-9), 454-459.

[14] Saghebjoo, M.; Sadeghi-Tabas, S.; Saffari, I.; Ghane, A.; Dimauro, I. Sex differences in antiaging response to short-and long-term high-intensity interval exercise in rat cardiac muscle: Telomerase activity, total antioxidant/oxidant status. Chin. J. Physiol. 2019, 62(6), 261-266.

[15] Cawthon, R.M.; Smith, K.R.; O'Brien, E.; Sivatchenko, A.; Kerber, R.A. Association between telomere length in blood and mortality in people aged 60 years or older. The Lancet 2003, 361(9355), 393-395.

[16] Vera, E.; Bernardes de Jesus, B.; Foronda, M.; Flores, J.; Blasco, M. The rate of increase of short telomeres predicts longevity in mammals. Cell Rep. 2012, 2, 732-737.

[17] Opresko, P.L.; Shay, J.W. Telomere-associated aging disorders. Ageing Res. Rev. 2017, 33, 52-66.

[18] Hiyama, E.; Hiyama, K. Telomerase as tumor marker. Cancer Lett. 2003, 194(2), 221-233. 
[19] Camp, E.R.; Summy, J.; Bauer, T.W.; Liu, W.; Gallick, G.E.; Ellis, L.M. Molecular mechanisms of resistance to therapies targeting the epidermal growth factor receptor. Clin. Cancer Res. 2005, 11(1), 397405.

[20] Delhommeau, F.; Thierry, A.; Feneux, D.; Lauret, E.; Leclercq, E.; Courtier, M.H.; Sainteny, F.; Vainchenker, W.; Bennaceur-Griscelli, A. Telomere dysfunction and telomerase reactivation in human leukemia cell lines after telomerase inhibition by the expression of a dominant-negative hTERT mutant. Oncogene 2002, 21(54), 8262-8271.

[21] Shay JW. Telomerase as a target for cancer therapeutics. Gene-Based Therapies for Cancer, Springer, 2010. pp 231-249.

[22] Herskowitz, I. Functional inactivation of genes by dominant negative mutations. Nature 1987, 329(6136), 219-222.

[23] Sheppard, D. Dominant negative mutants: tools for the study of protein function in and in vivo. Am. J. Respirat. Cell and Mol. Bio. 1994, 11(1), 1-6.

[24] Gabet, A.-S.; Mortreux, F.; Charneau, P.; Riou, P.; Duc-Dodon, M.; Wu, Y.; Jeang, K.-T.; Wattel, E. Inactivation of hTERT transcription by Tax. Oncogene 2003, 22(24), 3734-3741.

[25] Kitagawa, Y.; Kyo, S.; Takakura, M.; Kanaya, T.; Koshida, K.; Namiki, M.; Inoue, M. Demethylating reagent 5-azacytidine inhibits telomerase activity in human prostate cancer cells through transcriptional repression of hTERT. Clin. Cancer Res. 2000, 6(7), 2868-2875.

[26] Haaf, T. The effects of 5-azacytidine and 5-azadeoxycytidine on chromosome structure and function: implications for methylation-associated cellular processes. Pharmacol. Therap. 1995, 65(1), 19-46.

[27] Wang, Q.; Bai, Z.; Li, X.; Hou, L.; Zhang, B. The evidences of human orphan receptor COUP-TFII inhibiting telomerase activity through decreasing hTERT transcription. Cancer Lett. 2004, 214(1), 81-90.

[28] Yu, X.; Baer, R. Nuclear localization and cell cycle-specific expression of CtIP, a protein that associates with the BRCA1 tumor suppressor. J. Bio. Chem. 2000, 275(24), 18541-1859.

[29] Li, H.; Lee, T.-H.; Avraham, H. A. Novel tricomplex of BRCA1, Nmi, and c-Myc inhibits c-Myc-induced human telomerase reverse transcriptase gene (hTERT) promoter activity in breast cancer. J. Bio. Chem. 2002, 277(23), 20965-20973.

[30] Ruden, M.; Puri, N. Novel anticancer therapeutics targeting telomerase. Cancer Treatment Rev. 2013, 39(5), 444-456.

[31] Pascolo, E.; Wenz, C.; Lingner, J.; Hauel, N.; Priepke, H.; Kauffmann, I.; Garin-Chesa, P.; Rettig, W.J.; Damm, K.; Schnapp, A. Mechanism of human telomerase inhibition by BIBR1532, a synthetic, nonnucleosidic drug candidate. J. Bio. Chem. 2002, 277(18), 15566-15572.

[32] Sridhar, S.; Uhl, K.L.; Khudur, B.; Mishra, B.R.; Smart, R.C.; Schroeder, W. Qualitative analysis of the biological testing of novel telomerase inhibitors. Int. J. Drug Dev. Res. 2019, 11, 15-21.

[33] White, L.K.; Wright, W.E.; Shay, J.W. Telomerase inhibitors. Trends Biotechnol. 2001, 19(3), 114-120.

[34] Harrison, J.G.; Frier, C.; Laurant, R.; Dennis, R.; Raney, K.D.; Balasubramanian, S. Inhibition of human telomerase by PNA-cationic peptide conjugates. Bioorg. Med. Chem. Lett. 1999, 9(9), 1273-1278.

[35] Banack, S.A.; Metcalf, J.S.; Jiang, L.; Craighead, D.; Ilag, L.L.; Cox, P.A. Cyanobacteria produce N-(2-aminoethyl) glycine, a backbone for peptide nucleic acids which may have been the first genetic molecules for life on earth. PLoS One 2012, 7(11), e49043.

[36] Djojosubroto, M.W.; Chin, A.C.; Go, N.; Schaetzlein, S.; Manns, M.P.; Gryaznov, S.; Harley, C.B.; Rudolph, K.L. Telomerase antagonists GRN163 and GRN163L inhibit tumor growth and increase chemosensitivity of human hepatoma. Hepatology. 2005, 42(5), 1127-1136.

[37] Asai, A.; Oshima, Y.; Yamamoto, Y.; Uochi, T.-A.; Kusaka, H.; Akinaga, S.; Yamashita, Y.; Pongracz, K.; Pruzan, R.; Wunder, E.; Piatyszek, M.; Li, S.; Chin, A.C.; Harley, C.B.; Gryaznov, S. A novel telomerase template antagonist (GRN163) as a potential anticancer agent. Cancer Res. 2003, 63(14), 3931-3939.

[38] Herbert, B.-S.; Gellert, G.C.; Hochreiter, A.; Pongracz, K.; Wright, W.E.; Zielinska, D.; Chin, A.C.; Harley, C.B.; Shay, J.W.; Gryaznov, S.M. Lipid modification of GRN163, an N3' $\rightarrow$ P5' thiophosphoramidate oligonucleotide, enhances the potency of telomerase inhibition. Oncogene 2005, 24(33), 5262-5268.

[39] Autexier, C. Telomerase as a possible target for anticancer therapy. Chem. \& Biol. 1999, 6(11), R299R303.

[40] Vonderheide, R.H.; Hahn, W.C.; Schultze, J.L.; Nadler, L.M. The telomerase catalytic subunit is a widely expressed tumor-associated antigen recognized by cytotoxic T lymphocytes. Immunity 1999, 10(6), 673679.

[41] Brunsvig, P.F.; Aamdal, S.; Gjertsen, M.K.; Kvalheim, G.; Markowski-Grimsrud, C.J.; Sve, I.; Dyrhaug, M.; Trachsel, S.; Moller, M.; Eriksen, J.A.; Gaudernack, G. Telomerase peptide vaccination: a phase I/II study in patients with non-small cell lung cancer. Cancer Immunol. Immunotherap. 2006, 55(12), 1553 1564. 
[42] Shaw, V.; Naisbitt, D.; Costello, E.; Greenhalf, W.; Park, B.; Neoptolemos, J.; Middleton, G.W. Current status of GV1001 and other telomerase vaccination strategies in the treatment of cancer. Expert Rev. Vaccines. 2010, 9(9), 1007-1016.

[43] Inderberg-Suso, E.-M.; Trachsel, S.; Lislerud, K.; Rasmussen, A.-M.; Gaudernack, G. Widespread CD4+ T-cell reactivity to novel hTERT epitopes following vaccination of cancer patients with a single hTERT peptide GV1001. Oncoimmunology 2012, 1(5), 670-686.

[44] Kyte, J.A. Cancer vaccination with telomerase peptide GV1001. Expert Opin. Investigat. Drugs. 2009, 18(5), 687-694.

[45] Huo, L.; Tang, J.; Huang, J.; Huang, P.; Huang, C.; Kung, H.; Lin, M.C. Cancer immunotherapy targeting the telomerase reverse transcriptase. Cell Mol. Immunol. 2006, 3(1), 1-11.

[46] Su Z, Dannull J, Yang BK, Dahm P, Coleman D, Yancey D, Sichi, S.; Niedzwiecki, D.; Boczkowski, D.; Gilboa, G.; Vieweg, J. Telomerase mRNA-transfected dendritic cells stimulate antigen-specific CD8+ and CD4+ $\mathrm{T}$ cell responses in patients with metastatic prostate cancer. J. Immunology. 2005, 174(6), 3798-807.

[47] Carrozza, F.; Santoni, M.; Piva, F.; Cheng, L.; Lopez-Beltran, A.; Scarpelli, M.; Montironi, R.; Battelli, N.; Tamberi, S. Emerging immunotherapeutic strategies targeting telomerases in genitourinary tumors. Crit. Rev. Oncol/Hematol. 2018, 131, 1-6.

[48] Mender, I.; Dikmen, Z.G.; Wright, W.E.; Shay, J.W. Cancer cell immortality: Targeting telomerase. Holland-Frei Cancer Med. 2016, 1-9.

[49] Fujiwara, T.; Urata, Y.; Tanaka, N. Therapeutic Targets and Drugs IV: Telomerase-Specific Gene and Vector-Based Therapies for Human Cancer. Telomeres and Telomerase in Cancer, Springer; 2009. pp. 293-312.

[50] Karjoo, Z.; Ganapathy, V.; Hatefi, A. Gene-directed enzyme prodrug cancer therapy. Gene Therapy of Cancer: Elsevier, 2014, pp 77-91.

[51] Skelly, J.V.; Sanderson, M.R.; Suter, D.A.; Baumann, U.; Read, M.A.; Gregory, D.S.; Bennett, M.; Hobbs, S.M.; Neidle, S. Crystal structure of human DT-diaphorase: a model for interaction with the cytotoxic prodrug 5-(aziridin-1-yl)-2,4-dinitrobenzamide (CB1954). J. Med. Chem. 1999, 42(21), 43254330 .

[52] Neidle, S. Human telomeric G-quadruplex: The current status of telomeric G-quadruplexes as therapeutic targets in human cancer. The FEBS J. 2010, 277(5), 1118-1125.

[53] Shammas, M.A.; Reis, R.J.S.; Li, C.; Koley, H.; Hurley, L.H.; Anderson, K.C.; Munshi, N.C. Telomerase inhibition and cell growth arrest after telomestatin treatment in multiple myeloma. Clin. Cancer Res. 2004, 10(2), 770-776.

[54] Zhou, G.; Liu, X.; Li, Y.; Xu, S.; Ma, C.; Wu, X.; Cheng, Y.; Yu, Z.; Zhao, G.; Chen, Y. Telomere targeting with a novel G-quadruplex-interactive ligand BRACO-19 induces T-loop disassembly and telomerase displacement in human glioblastoma cells. Oncotarget 2016, 7(12), 14925-14939.

[55] Cookson, J.C.; Dai, F.; Smith, V.; Heald, R.A.; Laughton, C.A.; Stevens, M.F.; Burger, A.M. Pharmacodynamics of the G-quadruplex-stabilizing telomerase inhibitor 3,11-difluoro-6,8, 13-trimethyl$8 \mathrm{H}$-quino[4,3,2-kl]acridinium methosulfate (RHPS4) in vitro: activity in human tumor cells correlates with telomere length and can be enhanced, or antagonized, with cytotoxic agents. Mol. Pharm. 2005, 68(6), 1551-1558.

[56] Koga, F.; Kihara, K.; Neckers, L. Inhibition of cancer invasion and metastasis by targeting the molecular chaperone heat-shock protein 90. Anticancer Res. 2009, 29(3), 797-807.

[57] Rezler, E.M.; Bearss, D.J.; Hurley, L.H. Telomeres and telomerases as drug targets. Curr. Opin. Pharmacol. 2002, 2(4), 415-423.

[58] Holt, S.E.; Aisner, D.L.; Baur, J.; Tesmer, V.M.; Dy, M.; Ouellette, M.; Trager, J.B.; Morin, G.B.; Toft, D.O.; Shay, J.W.; Wright, W.E.; White, M.A. Functional requirement of p23 and Hsp90 in telomerase complexes. Genes Develop. 1999, 13(7), 817-826.

[59] Powers, M.V.; Workman, P. Targeting of multiple signalling pathways by heat shock protein 90 molecular chaperone inhibitors. Endoc. Related Cancer. 2006, 13(1), S125-S135. 
[60] Wenkert, D.; Ramirez, B.; Shen, Y.; Kron, M.A. In vitro activity of geldanamycin derivatives against Schistosoma japonicum and Brugia malayi. J. Parasitology Res. 2010, 1-7.

[61] Ochel, H.J.; Eichhorn, K.; Gademann, G. Geldanamycin: The prototype of a class of antitumor drugs targeting the heat shock protein 90 family of molecular chaperones. Cell Stress Chaper. 2001, 6(2), 105 112.

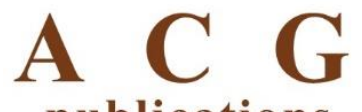

publications

(C) 2020 ACG Publications 